\title{
Thermal reconstruction behavior of the quenched hydroxyapatite powder during reheating in air
}

\author{
Feng-Huei Lin ${ }^{\text {a }, *}$, Liao Chun-Jen ${ }^{\text {a }}$, Chen Ko-Shao ${ }^{\mathrm{b}}$, Sun Jui-Sheng ${ }^{\mathrm{c}}$ \\ ${ }^{a}$ Institute of Biomedical Engineering, College of Medicine, National Taiwan University, Taipei, 100 Taiwan \\ ${ }^{\mathrm{b}}$ Department of Material Engineering, Tatung Institute of Technology, Taipei, Taiwan \\ ${ }^{c}$ Department of Orthopaedic Surgery, College of Medicine, National Taiwan University, Taipei, Taiwan
}

\begin{abstract}
Commercial hydroxyapatite (HAP) powders were quenched from $1500^{\circ} \mathrm{C}$ to room temperature and reheated at different temperatures by a program controlled $\mathrm{SiC}$-heated furnace to investigate the reconstruction behavior of quenched HAP powder in air. X-ray diffractometer (XRD) and Fourier-transformed infrared (FTIR) analysis were used to examine changes in crystalline phases and functional groups of quenched HAP powders at different temperatures. Weight changes of the quenched powders during heating were recorded by thermogravimetric analysis (TGA). The XRD results showed that the quenched HAP powder was composed of two crystalline phases of tetracalcium phosphate (TTCP) and $\alpha$-tricalcium phosphate $(\alpha \mathrm{TCP})$. There was no other calcium phosphate phases to be traced. When quenched HAP powders were reheated, TTCP gradually reconstructed into $\mathrm{HAP}$ around $500^{\circ} \mathrm{C}$ and yield $\mathrm{Ca}(\mathrm{OH})_{2}$. $\alpha \mathrm{TCP}$ did not convert to HAP at a temperature lower than $700^{\circ} \mathrm{C}$ but the transformation of $\alpha \mathrm{TCP}$ to $\beta \mathrm{TCP}$ was observed during heating. $\alpha \mathrm{TCP}$ reacted with $\mathrm{Ca}(\mathrm{OH})_{2}$, the product of reconstruction of TTCP, to form more HAP at temperatures over $700^{\circ} \mathrm{C}$. In addition, the $\mathrm{CO}_{3}^{2-}$ ion was incorporated into the lattice of the reconstructed $\mathrm{HAP}$ around $500^{\circ} \mathrm{C}$. The intensity of $\mathrm{CO}_{3}^{2-}$ ion in FTIR decreased as the temperature increased and totally disappeared around $900^{\circ} \mathrm{C}$. Above $1000^{\circ} \mathrm{C}$, reconstructed $\mathrm{HAP}$ lost $\mathrm{OH}$ ions and transformed into oxyhydroapatite. (C) 2000 Elsevier Science S.A. All rights reserved.
\end{abstract}

Keywords: Hydroxyapatite; Plasma-spray; Decomposition; Reconstruction

\section{Introduction}

Hydroxyapatite [HAP, $\mathrm{Ca}_{10}\left(\mathrm{PO}_{4}\right)_{6}(\mathrm{OH})_{2}$ ] is the main mineral constituent of human bone. It has been developed and made available for experimental or clinical application because of its excellent biocompatibility, faster bone regeneration, and direct bonding to regenerated bone without intermediate connective tissue [1-3]. In recent years, as a means of improving the biocompatibility of metal materials in vivo, coating HAP onto metal implant surfaces using a plasma-spraying technique has been widely investigated [4-6]. Such coatings should inject HAP powder into a plasma, which are then heated to very high temperatures (usually over $10000^{\circ} \mathrm{C}$ ) and propelled to cold metal substrates (usually below $150^{\circ} \mathrm{C}$ ) at high speeds to form coatings on the surfaces of metals [6,7]. These extreme

\footnotetext{
* Corresponding author. Tel.: +886-2-23970800; fax: +886-223940049.

E-mail address: double@hgmc.ntu.edu.tw (F.-H. Lin).
}

heat-treatment conditions then lead to the formation of non-crystalline or metastable crystalline products such as oxyhydroxyapatite (OHAP, $\mathrm{Ca}_{10}\left(\mathrm{PO}_{4}\right)_{6}(\mathrm{OH})_{2-X} \mathrm{O}_{X} \square_{X}$ ), $\alpha$-tricalcium phosphate $\left(\alpha \mathrm{TCP}, \mathrm{Ca}_{3}\left(\mathrm{PO}_{4}\right)_{2}\right)$, tetracalcium phosphate (TTCP, $\mathrm{Ca}_{4} \mathrm{P}_{2} \mathrm{O}_{9}$ ), calcium oxide $(\mathrm{CaO})$ and amorphous apatite in HAP coatings [8-10]. It has been reported that OHAP, TTCP and $\alpha$ TCP undergo dissolution and degradation more rapidly than HAP in an aqueous environment [11], which decreases chemical stability and enhances degradation of the coatings in vivo.

Recently, various plasma-spraying conditions and postheat treatments have been studied for increasing the crystallinity of HAP coatings $[8,12,13]$. However, these coatings contain numerous amorphous phases and complicated metastable phases, which make elucidation of the reconstruction behavior of HAP coatings during post-heat treatment difficult. In the studies, commercial HAP powders were heated to $1500^{\circ} \mathrm{C}$ and quenched to room temperature. The quenched powders were reheated to different temperatures to investigate the reconstruction behavior of HAP 
during post-heat treatment. XRD analysis was used to examine the phase transformation of HAP quenched pow-

(a)
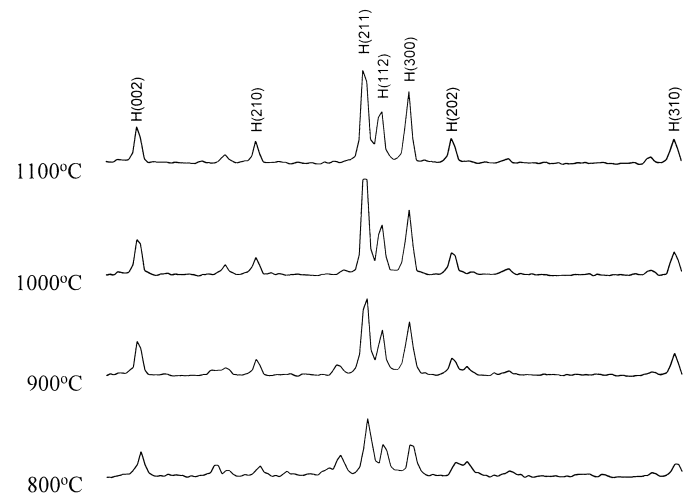

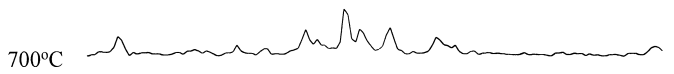

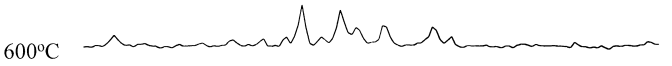

${ }_{500^{\circ} \mathrm{C} \text { ormonn }}$

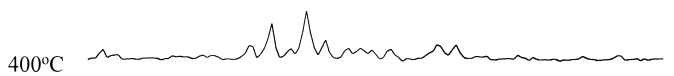

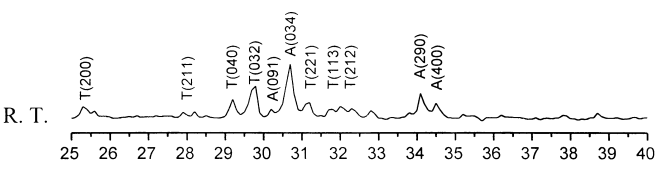

ders at different temperatures. The functional group changes of specimens at different temperatures were ob-

(b)
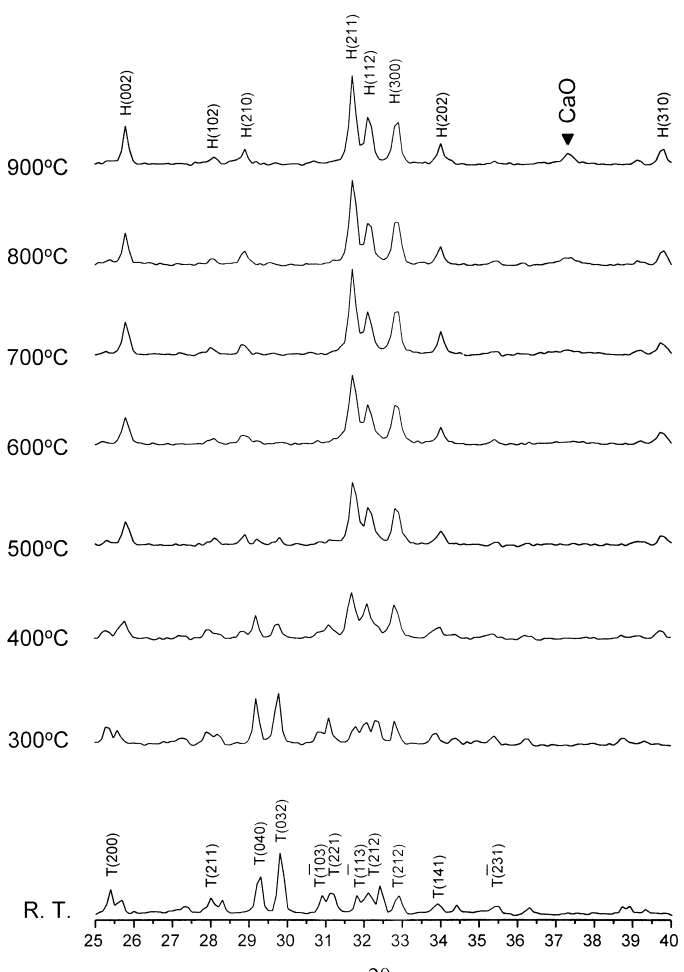

$2 \theta$

(c)

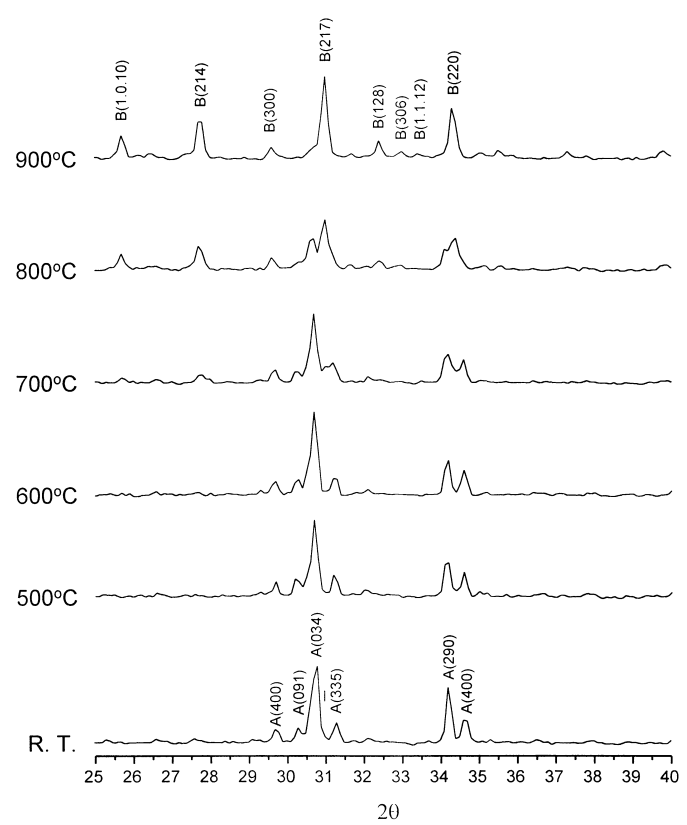

Fig. 1. (a) X-ray diffraction patterns of quenched HAP powder reheated at different temperatures (H: HAP, T: TTCP, A: $\alpha$ TCP ) (b) X-ray diffraction patterns of TTCP heated at different temperatures (H: HAP, T: TTCP ) (c) X-ray diffraction patterns of $\alpha$ TCP heated at different temperatures (A: $\alpha$ TCP, B: $\beta$ TCP ). 
served by FTIR spectroscopy, and the weight changes were recorded by thermogravimetric analysis (TGA) during heating.

\section{Materials and methods}

HAP powder was purchased from E. Merck, 64271 Darmstadt, Germany. It was placed in covered platinum crucibles and heated to $1500^{\circ} \mathrm{C}$ at the rate of $10^{\circ} \mathrm{C} / \mathrm{min}$ in a SiC-heated furnace, and then maintained for $1 \mathrm{~h}$. The HAP powder was then quenched to room temperature. To investigate the reconstruction behavior of quenched HAP powder, we reheated the quenched powder at different temperatures $\left(400-1100^{\circ} \mathrm{C}\right.$ for $\left.1 \mathrm{~h}\right)$ and then quenched the powder to room temperature again.

TTCP and $\alpha$ TCP were heated at different temperatures to investigate their thermal behavior individually during heating. TTCP was synthesized by heating an equimolar mixture of commercially obtained $\mathrm{CaCO}_{3}$ and $\mathrm{CaHPO}_{4}$ (May and Baker, Dagenham, UK; Sigma, USA) at $1500^{\circ} \mathrm{C}$ for $1 \mathrm{~h}$ in a furnace and then quenching the mixture to room temperature. $\alpha$ TCP was prepared by mixing HAP and $\mathrm{CaHPO}_{4}$ with a molar ratio of $2: 1$. The mixture was heated in air for $1 \mathrm{~h}$ at $1400^{\circ} \mathrm{C}$ and then quenched to room temperature.

(a)

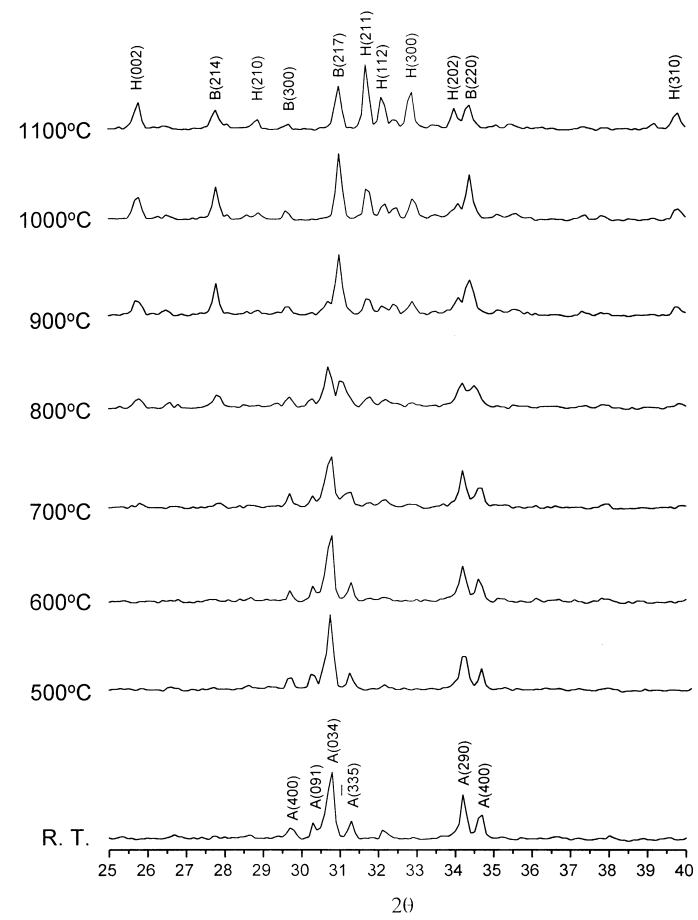

The crystalline phases of specimens were determined by Rigaku X-ray powder diffractometry with $\mathrm{CuK}_{\alpha}$ radiation and $\mathrm{Ni}$ filter. The scanning range of the samples was from $10^{\circ}$ to $60^{\circ}$ with a scanning speed of $4^{\circ} / \mathrm{min}$. The infrared spectra were recorded using $\mathrm{KBr}$ pellets (1-mg sample/ 300-mg KBr) on a Jasco FTIR grating instrument with slow scan and normal-slit width. The weight change of the specimens during heating and cooling were recorded by TGA in the heating range of $20-1500^{\circ} \mathrm{C}$ with a heating rate of $10^{\circ} \mathrm{C} / \mathrm{min}$ under a flowing air atmosphere.

\section{Results}

\subsection{Crystal structure analysis}

Fig. 1a summarizes the XRD patterns of quenched HAP powder reheated at different temperatures. The quenched HAP powder showed a TTCP $/ \alpha$ TCP biphasic crystalline structure (Fig. 1a - R.T.). There were no other calcium phosphate crystalline phases to be observed while the HAP powder was quenched from $1500^{\circ} \mathrm{C}$ and reheated to $400^{\circ} \mathrm{C}$. When the reheating temperature was over $500^{\circ} \mathrm{C}$, the peaks of HAP gradually burgeoned out and the characteristic peaks of TTCP gradually decreased in intensity. But the peaks for $\alpha$ TCP did not show any changes in intensity. At $700^{\circ} \mathrm{C}$, a part of $\alpha \mathrm{TCP}$ was transformed into $\beta \mathrm{TCP}$ which

(b)

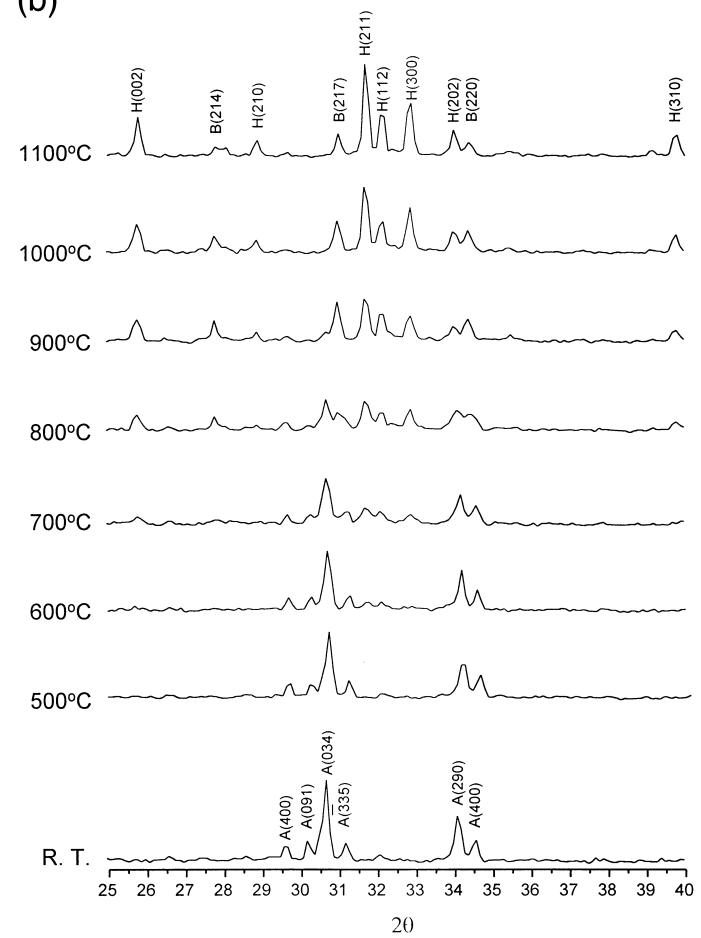

Fig. 2. (a) X-ray diffraction patterns of the mixture of $\alpha \mathrm{TCP}$ and $\mathrm{CaO}$ with a molar ratio of 3:1 heated at different temperatures (A: $\alpha \mathrm{TCP}, \mathrm{B}$ : $\beta \mathrm{TCP}$, $\mathrm{H}$ : HAP) (b) X-ray diffraction patterns of the mixture of $\alpha \mathrm{TCP}$ and $\mathrm{Ca}(\mathrm{OH})_{2}$ with a molar ratio of 3:1 heated at different temperatures (A: $\alpha \mathrm{TCP}, \mathrm{B}$ : $\beta \mathrm{TCP}$, H: HAP). 
(a)

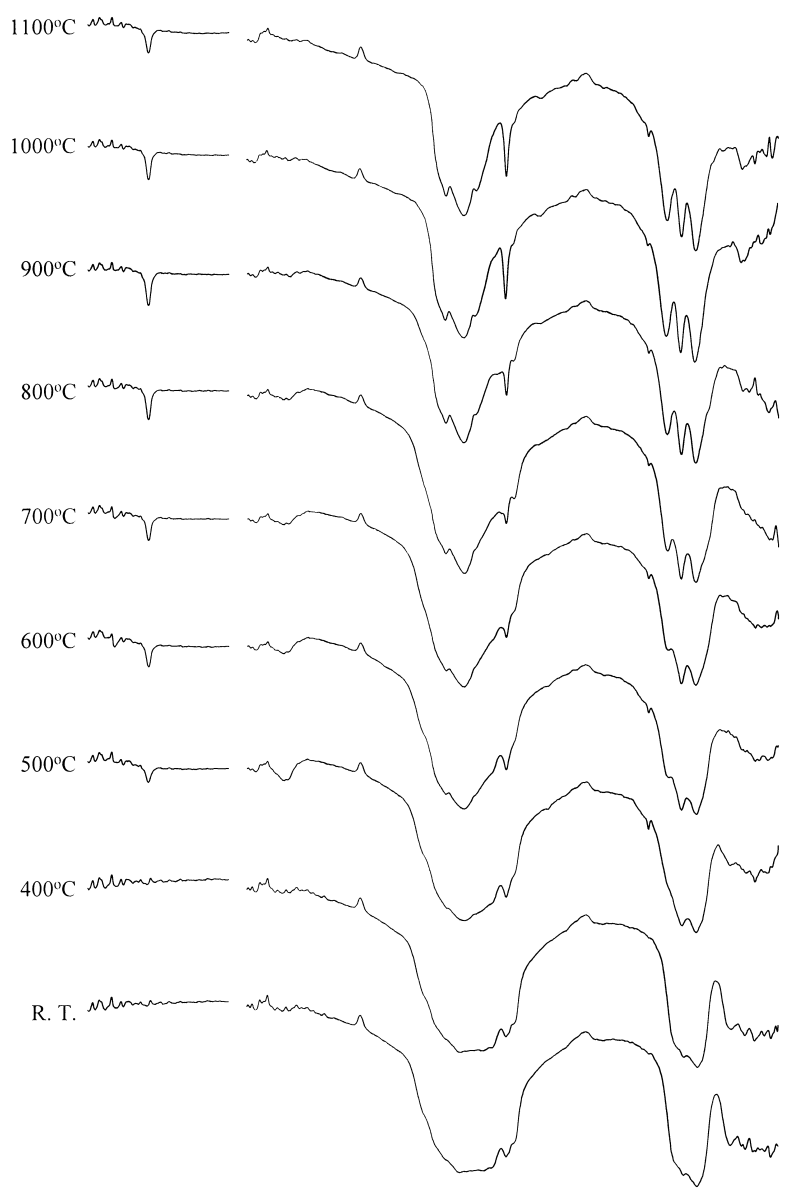

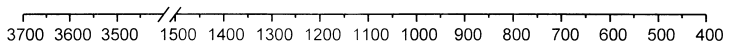
Wavenumber[cm-1] (b)

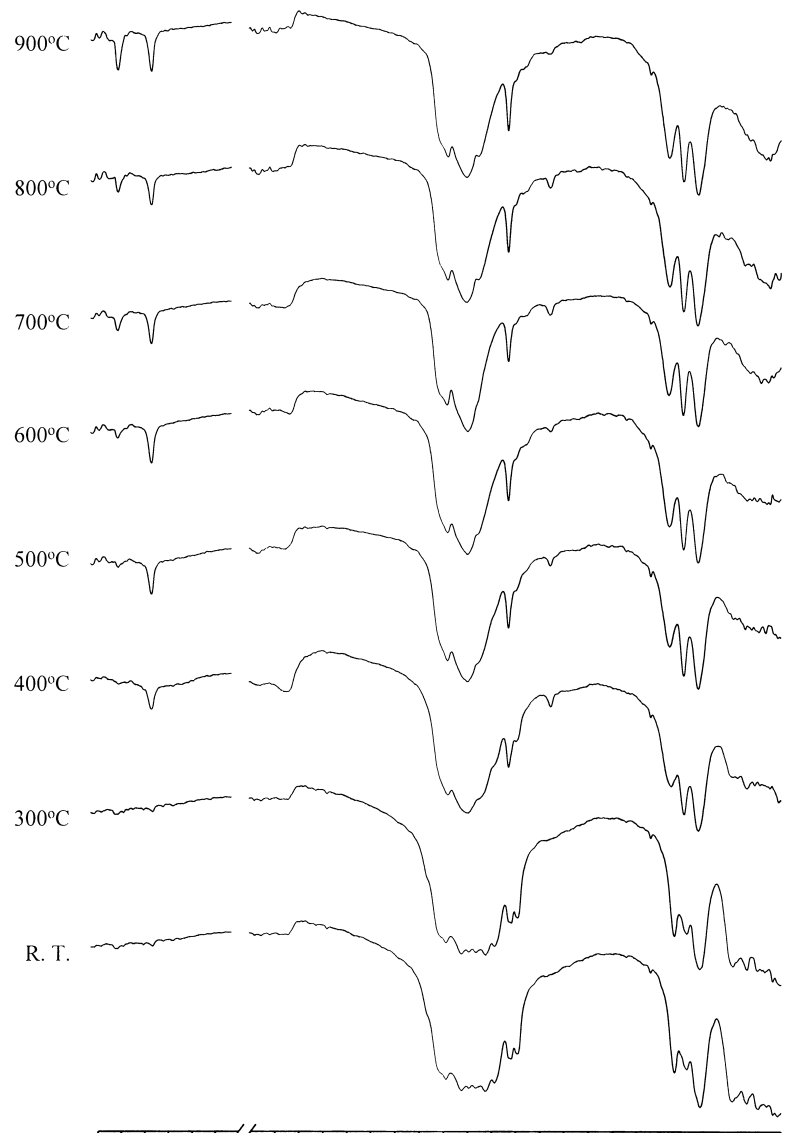

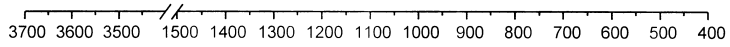
Wavenumber[cm-1]

(c)

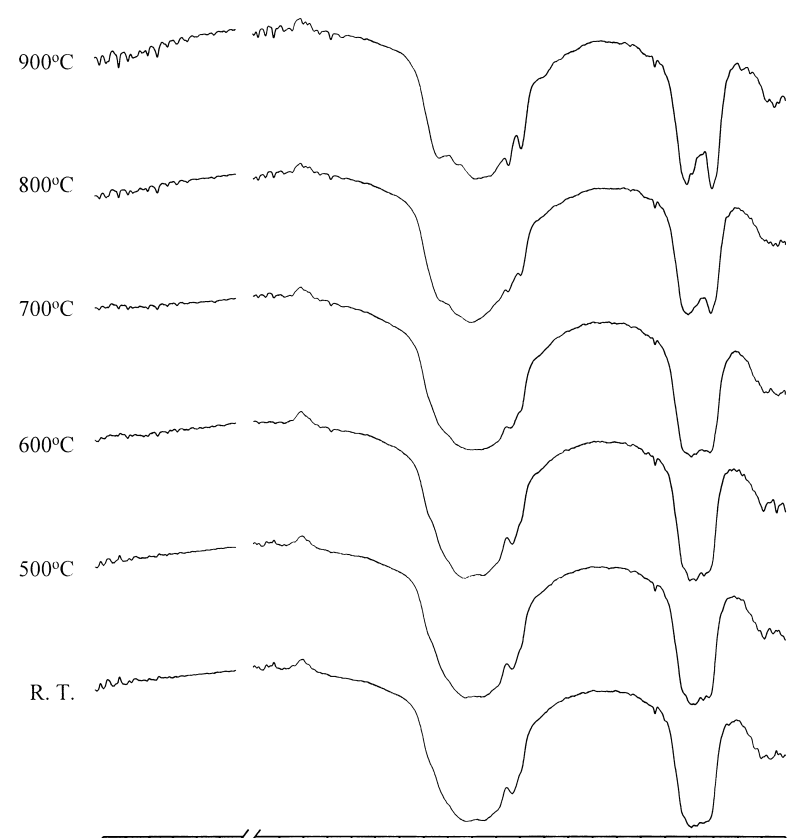

$\begin{array}{lllllllllllllll}3700 & 3600 & 1500 & 1500 & 1400 & 1300 & 1200 & 1100 & 1000 & 900 & 800 & 700 & 600 & 500 & 400\end{array}$ Wavenumber|cm-1] 


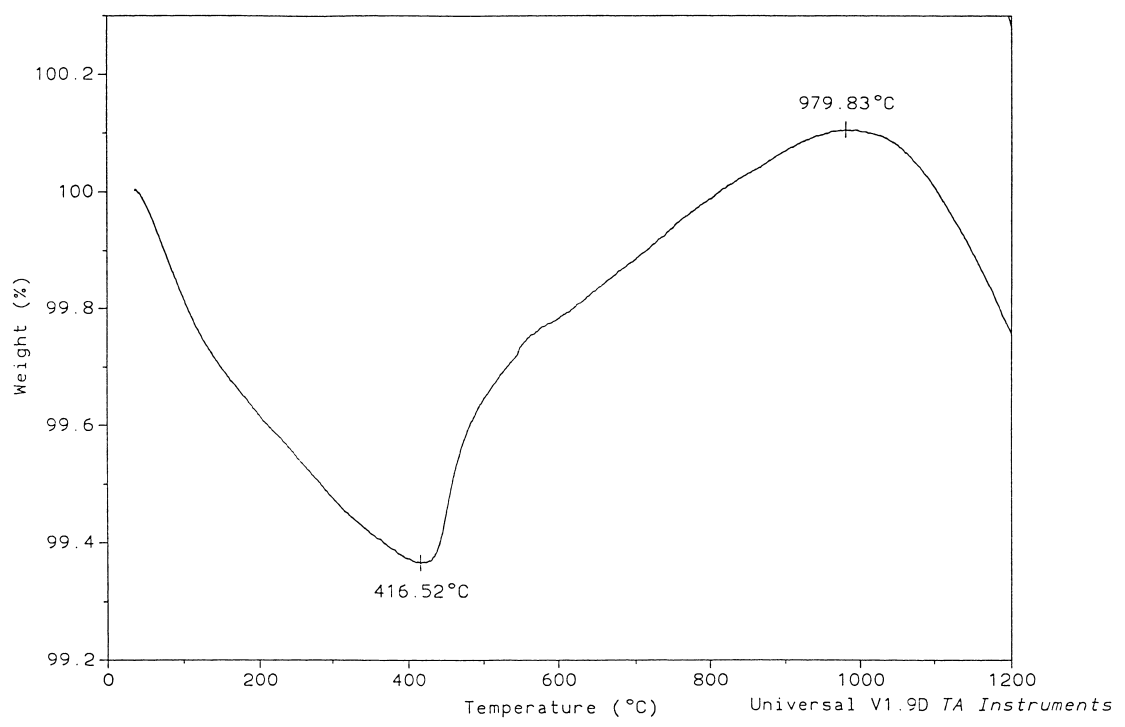

Fig. 4. TGA result of quenched HAP powder heated from room temperature to $1200^{\circ} \mathrm{C}$.

caused the peaks of $\alpha$ TCP to decrease slightly. TTCPcharacterized peaks reheated to a temperature above $900^{\circ} \mathrm{C}$ completely disappeared because all the TTCP was converted to HAP. This same scenario occurred on $\alpha \mathrm{TCP}$ to $\beta$ TCP transformation. $\alpha$ TCP gradually turned into $\beta$ TCP with reheated temperature increases, and the peaks of $\alpha \mathrm{TCP}$ totally disappeared when the temperature reached $900^{\circ} \mathrm{C}$. At temperatures up to $1100^{\circ} \mathrm{C}$, only HAP was observed in the XRD pattern.

To further understand the phase transformation of both TTCP and $\alpha$ TCP during heating, TTCP and $\alpha$ TCP were separately prepared and heated to different temperatures. As seen in Fig. 1b, TTCP were gradually converted to HAP at temperatures over $400^{\circ} \mathrm{C}$. Above $700^{\circ} \mathrm{C}$, the main characteristic peak of $\mathrm{CaO}$ burgeoned out on the XRD pattern, and its intensity increased as the reheating temperature increased. Fig. 1c shows the XRD results of $\alpha \mathrm{TCP}$ heated at different temperatures. At $700^{\circ} \mathrm{C}$, a part of $\alpha \mathrm{TCP}$ would transform to $\beta \mathrm{TCP}$. When the temperature rose to $900^{\circ} \mathrm{C}$, all the $\alpha \mathrm{TCP}$ were converted to $\beta \mathrm{TCP}$. There were no HAP-characterized peaks observed during heating.

Fig. 2a shows the XRD patterns of the mixture of $\alpha \mathrm{TCP}$ and $\mathrm{CaO}$ with a molar ratio of $3: 1$, heated at different temperatures in an air atmosphere. The phase transformation of $\alpha \mathrm{TCP}$ to $\beta \mathrm{TCP}$ occurred around $700^{\circ} \mathrm{C}$. The characterized peaks of HAP appeared at a temperature of $900^{\circ} \mathrm{C}$ and the intensity increased with the temperature increase. XRD results of the mixture of $\alpha \mathrm{TCP}$ and $\mathrm{Ca}(\mathrm{OH})_{2}$ with a molar ratio of 3:1 heated from room temperature to $1100^{\circ} \mathrm{C}$ are shown in Fig. 2b. $\alpha \mathrm{TCP}$ started to transform into $\beta \mathrm{TCP}$ at $700^{\circ} \mathrm{C}$. At that time, HAP-characterized peaks on the XRD pattern were seen and the peaks increased in intensity as reheating temperatures increased.

\subsection{FTIR spectrum analysis}

The FTIR spectra of quenched HAP powders reheated at different temperatures are summarized in Fig. 3a. There was no significant difference in the FTIR spectrum when the reheated temperature increased from room temperature to $400^{\circ} \mathrm{C}$. The spectrum was in agreement with that of TTCP and $\alpha$ TCP. As the heating temperature increased, broad bands for TTCP and $\alpha$ TCP in the region of 1200 to $950 \mathrm{~cm}^{-1}$ would gradually narrow down. An $\mathrm{OH}^{-}$ stretching band at $3572 \mathrm{~cm}^{-1}$ and a small $\mathrm{OH}^{-}$librational band at $635 \mathrm{~cm}^{-1}$ appeared at $500^{\circ} \mathrm{C}$, where their intensity increased with the temperature increase. Above $1000^{\circ} \mathrm{C}$, the intensity of the two $\mathrm{OH}^{-}$absorption bands would gradually decrease. Additionally, the intensity of the structural $\mathrm{CO}_{3}^{2-}$ bands at $1470-1412 \mathrm{~cm}^{-1}$ had a positive tendency when the reheated temperature increased from room temperature to $500^{\circ} \mathrm{C}$. Thereafter, the bands gradually decreased as the temperature increased and completely disappeared around $900^{\circ} \mathrm{C}$.

Fig. 3b summarizes the FTIR spectrum of TTCP heated at different temperatures. There were no significant differences in FTIR spectra between room temperature and $300^{\circ} \mathrm{C}$. At $400^{\circ} \mathrm{C}, \mathrm{PO}_{4}^{3-}$ bands of $\mathrm{HAP}$ appeared at 960 , 1075 , and $1100 \mathrm{~cm}^{-1}$. $\mathrm{OH}^{-}$bands of HAP at 3572 and $635 \mathrm{~cm}^{-1}$ could also be traced. An absorption band at $3640 \mathrm{~cm}^{-1}$ corresponding to $\mathrm{H}_{2} \mathrm{O}$ was observed at $500^{\circ} \mathrm{C}$, where the intensity increased with the reheated tempera-

Fig. 3. (a) FTIR spectra of quenched HAP powder reheated at different temperatures (b) FTIR spectra of TTCP heated at different temperatures (c) FTIR spectra of $\alpha \mathrm{TCP}$ heated at different temperatures. 
ture. When $\alpha$ TCP was reheated at different temperatures (as seen in Fig. 3c), the bands for TCP gradually burgeoned out at 1118, 973, 945, 603, 586, 649 and $540 \mathrm{~cm}^{-1}$ around $700^{\circ} \mathrm{C}$, where their intensity also increased as the temperature increased. $\mathrm{OH}^{-}$bands were not detected in any one of FTIR spectrum.

\subsection{Thermogravimetric analysis}

Fig. 4 shows the thermogravimetric curve of HAP quenched powder heated from room temperature to $1200^{\circ} \mathrm{C}$. At temperatures in the range from room temperature to $415^{\circ} \mathrm{C}$, the HAP quenched powder quickly lost weight. A turning point was observed at $415^{\circ} \mathrm{C}$ and then a fast weight increase occurred. At temperatures up to $600^{\circ} \mathrm{C}$, the weight of HAP quenched powder increased gradually at a moderate rate. Above $980^{\circ} \mathrm{C}$, the sample weight did not increase but rather decreased as the temperature increased.

\section{Discussion}

During the last decade, plasma-sprayed HAP coatings have become increasingly popular in the field of prosthetic replacements. To deposit HAP on metal surfaces, HAP powder should be introduced to high temperatures, which would result in partial melting and decomposing to an amorphous or metaphase calcium phosphate. When the high temperature particles were impacted onto cold metal substrates, the cooling rate of coatings were as high as $10^{8 \circ} \mathrm{C} / \mathrm{s}$, which led to the formation of a large amount of non-crystalline or metastable crystalline products on HAP coatings. Studies in vitro and in vivo have been reported in which the biodegradation of HAP coatings depend on their crystallinity [13]. For increasing the crystallinity of HAP coatings, the reconstruction behavior of HAP has attracted more and more attention in recent years. Gross et al. [9] heated an amorphous phase of HAP coating in dry and moist atmospheres. The latter gave rise to more extensive crystallization. McPherson et al. [14] found that heat treatment of HAP coatings in air at $600^{\circ} \mathrm{C}$ resulted in crystallization of the glass phase and a reaction with water vapor forms HAP. Zyman et al. [8] heated HAP coatings at $630^{\circ} \mathrm{C}$, the temperature at which the amorphous phase was crystallized and completely crystalline HAP coatings were obtained. Chen et al. [12] studied increasing the crystallinity of HAP coatings by post-heat treatment and found that TTCP and $\alpha$ TCP could convert to HAP by hydrolytic reaction in humid atmospheres. They suggested that TTCP and $\alpha$ TCP be converted to HAP by a series of hydrolytic reactions:

$$
3 \mathrm{Ca}_{4} \mathrm{P}_{2} \mathrm{O}_{9}+3 \mathrm{H}_{2} \mathrm{O} \rightarrow \mathrm{Ca}_{10}\left(\mathrm{PO}_{4}\right)_{6}(\mathrm{OH})_{2}+2 \mathrm{Ca}(\mathrm{OH})_{2}
$$

and

$$
10 \mathrm{Ca}_{3}\left(\mathrm{PO}_{4}\right)_{2}+6 \mathrm{H}_{2} \mathrm{O} \rightarrow 3 \mathrm{Ca}_{10}\left(\mathrm{PO}_{4}\right)_{6}(\mathrm{OH})_{2}+2 \mathrm{H}_{3} \mathrm{PO}_{4}
$$

In this study, commercial HAP powders were decomposed to TTCP and $\alpha$ TCP at high temperatures. Some investigators reported that $\mathrm{CaO}$ could be observed while HAP decomposed $[15,16]$. However, only TTCP and $\alpha$ TCP crystalline phases appeared on the XRD pattern and no other calcium phosphate phases could be traced when HAP powder was quenched from $1500^{\circ} \mathrm{C}$ to room temperature (as seen in Fig. 1a). According to the phase diagram of $\mathrm{CaO} / \mathrm{P}_{2} \mathrm{O}_{5}$ [17], a liquid phase begins to form at $1570^{\circ} \mathrm{C}$ and the only solid phase existing above $1700^{\circ} \mathrm{C}$ is calcium oxide. $\mathrm{CaO}$ was not detected in the study because the decomposed temperature of HAP was lower than $1700^{\circ} \mathrm{C}$. In thermal spray or plasma spray processes, the temperature to melt $\mathrm{HAP}$ powder was over $10000^{\circ} \mathrm{C}$ which caused $\mathrm{CaO}$ to be left in the system while being quenched from such a high temperature.

When the HAP powder was quenched from $1500^{\circ} \mathrm{C}$, all the HAP would disappear and be decomposed into TTCP and $\alpha$ TCP. They are then supposed to be reconstructed into HAP when the quenched HAP powder is reheated up to $500^{\circ} \mathrm{C}$ (Fig.1a). It was worth noting that only TTCPcharacterized peaks decreased in intensity at a temperature of $500^{\circ} \mathrm{C}$, but the characteristic peaks for $\alpha \mathrm{TCP}$ did not change. This may reflect that the HAP at that temperature might directly transform from TTCP, where $\alpha$ TCP did not join in this reaction. Ribound [17] and Chow [18] suggested that TTCP is less stable than TCP because the crystal structure of TTCP is similar to HAP which promotes the crystal growth of HAP. To further understand the phase transformations of TTCP during heating, the TTCP were heated at different temperatures individually. As seen in Fig. 1b, TTCP were converted to HAP at the temperature of $400^{\circ} \mathrm{C}$. The results of FTIR analysis showed that the $\mathrm{OH}^{-}$bands were traced at temperatures up to $400^{\circ} \mathrm{C}$ (Fig. 3a). We believe that the hydrolytic reaction Eq. (1) — occurred in this system during heating. According to Eq. (1), TTCP would react with the $\mathrm{OH}^{-}$group to yield HAP and $\mathrm{Ca}(\mathrm{OH})_{2}$. It was difficult to trace the characteristic peaks of $\mathrm{Ca}(\mathrm{OH})_{2}$ in XRD patterns because most of the peaks were overlapped with those of HAP. However, the main characteristic peaks of $\mathrm{CaO}$ could be detected on the XRD pattern at temperatures above $700^{\circ} \mathrm{C}$ (Fig. 2a), accompanied by the appearance of $\mathrm{H}_{2} \mathrm{O}$ bands as seen in FTIR spectra (Fig. 3b). We proposed that $\mathrm{Ca}(\mathrm{OH})_{2}$ should exist in this system when TTCP was converted to $\mathrm{HAP}$ and $\mathrm{CaO}$ came from the dehydration of $\mathrm{Ca}(\mathrm{OH})_{2}$ during heating.

It is interesting that the characterized peaks for $\mathrm{CaO}$ or $\mathrm{Ca}(\mathrm{OH})_{2}$ did not show up in XRD patterns when quenched HAP powder (TTCP $/ \alpha$ TCP) was reheated. According to Eqs. (1) and (2), TTCP and TCP could be converted to 
HAP individually by hydrolytic reaction. However, only the transformation of $\alpha \mathrm{TCP}$ to $\beta \mathrm{TCP}$ was observed when we heated $\alpha \mathrm{TCP}$ from $500^{\circ} \mathrm{C}$ to $900^{\circ} \mathrm{C}$ (as seen in Fig. 1c). There were no HAP characteristic peaks observed in XRD patterns or $\mathrm{OH}^{-}$bands traced in the FTIR spectrum (Fig. $3 c$ ). These results reflected that $\alpha \mathrm{TCP}$ did not convert to HAP by heat-treatment in air atmosphere and no hydrolytic reaction occurred in the system. We suggested that $\alpha \mathrm{TCP}$ could not be converted to HAP in a quenched HAP powder (TTCP $/ \alpha \mathrm{TCP}$ ) as in the study. But $\alpha \mathrm{TCP}$ might react with $\mathrm{CaO}$ or $\mathrm{Ca}(\mathrm{OH})_{2}$ - the products of TTCP converted to HAP - and then turn into HAP. Chen et al. [12] heated a mixture of $\beta \mathrm{TCP}$ and $\mathrm{CaO}$ with a molar ratio of $3: 1$ at $650^{\circ} \mathrm{C}$ for $1 \mathrm{~h}$ in air and found that almost all the TCP were converted to HAP during heating, but most of the $\mathrm{CaO}$ in the mixture remained unchanged. Bonel et al. [19] studied an $\mathrm{HAP} / \mathrm{Ca}(\mathrm{OH})_{2}$ system and reported that TCP could react with $\mathrm{CaO}$ to lead to the formation of HAP at $1000^{\circ} \mathrm{C}$ in humid air, according to the reaction:

$3 \mathrm{Ca}_{3}\left(\mathrm{PO}_{4}\right)_{2}+\mathrm{CaO}+\mathrm{H}_{2} \mathrm{O} \rightarrow \mathrm{Ca}_{10}\left(\mathrm{PO}_{4}\right)_{6}(\mathrm{OH})_{2}$

In this study, we mixed $\alpha \mathrm{TCP}$ and $\mathrm{CaO}$ with a molar ratio of 3:1 and heated it at different temperatures in air. Results showed that $\alpha$ TCP reacted with $\mathrm{CaO}$ and then were converted to HAP around $900^{\circ} \mathrm{C}$ (Fig. 2a). If we heated the mixture of $\alpha \mathrm{TCP}$ and $\mathrm{Ca}(\mathrm{OH})_{2}$ with a molar ratio of $3: 1$, the reaction would occur at a lower temperature than $700^{\circ} \mathrm{C}$ (Fig. 2b). The temperature was in agreement with that of $\alpha$ TCP converted to HAP in the quenched HAP powder system. Therefore, we proposed that the reconstruction of quenched HAP powder (TTCP/ $\alpha \mathrm{TCP}$ ) during reheating was through the following reactions: Initially, TTCP would transform into $\mathrm{HAP}$ and $\mathrm{Ca}(\mathrm{OH})_{2}$ around $500^{\circ} \mathrm{C}$ by hydrolytic reaction [as seen in Eq. (1)]. $\mathrm{Ca}(\mathrm{OH})_{2}$, the product of TTCP hydrolytic reaction, could then react with $\alpha \mathrm{TCP}$ to yield more HAP by the equation of

$3 \mathrm{Ca}_{3}\left(\mathrm{PO}_{4}\right)_{2}+\mathrm{Ca}(\mathrm{OH})_{2} \rightarrow \mathrm{Ca}_{10}\left(\mathrm{PO}_{4}\right)_{6}(\mathrm{OH})_{2}$

When quenched HAP powder were reconstructed into HAP, the carbonate ions could be traced by FTIR at around $500^{\circ} \mathrm{C}$ (Fig. 3a). It is well known that carbonate ion is important in biological apatites [20]. Some reports showed that carbonated HAPs are more reactive than pure HAP in biological environments [21,22]. It has been reported that the carbonate content of plasma-sprayed HAP coatings could be obtained by immersing the coatings into physiologically simulated solution or by treating with carbonate atmosphere [23,24]. LeGeros et al. [25] assumed that the carbonate content could decrease the solubility of the HAP coating in a physiological environment. In this study, the appearance of the carbonate ions in the system reflected that the $\mathrm{CO}_{3}^{2-}$ ion could be incorporated into the HAP lattice simply by reheating quenched HAP powder in air.
When heating the whole bone, Biltz et al. [20] found that the structural $\mathrm{CO}_{3}^{2-}$ ion in the whole bone did not change at $450^{\circ} \mathrm{C}$. The structural $\mathrm{CO}_{3}^{2-}$ ion would gradually decrease at temperatures over $550^{\circ} \mathrm{C}$ and completely disappear around $900^{\circ} \mathrm{C}$. In this study, the carbonate ion in the reconstructed HAP also gradually decreased with reheated temperatures up to $500^{\circ} \mathrm{C}$ and totally disappeared around $900^{\circ} \mathrm{C}$. TGA curves showed that the weight of the reconstructed HAP decreased as the temperature increased over $980^{\circ} \mathrm{C}$ (Fig. 4). The bands of $\mathrm{OH}^{-}$ions in the reconstructed HAP also gradually decreased as the temperatures increased (Fig. 3a). The reconstructed HAP would gradually dehydrate and transform into OHAP during reheating, where the $\mathrm{CO}_{3}^{2-}$ ion and $\mathrm{OH}^{-}$ion would gradually be released from the lattice and lead to weight loss at temperatures over $900^{\circ} \mathrm{C}$.

\section{Conclusions}

When quenched HAP powder (TTCP / $\alpha \mathrm{TCP}$ ) were reheated, TTCP were reconstructed into HAP and yielded $\mathrm{Ca}(\mathrm{OH})_{2}$ at around $500^{\circ} \mathrm{C}$. $\alpha \mathrm{TCP}$ were not converted to HAP but the transformation of $\alpha$ TCP to $\beta$ TCP was observed during heating. $\alpha$ TCP reacted with $\mathrm{Ca}(\mathrm{OH})_{2}$, the product of reconstruction of TTCP, to form more HAP at the temperatures over $700^{\circ} \mathrm{C}$. In addition, the $\mathrm{CO}_{3}^{2-}$ ion was incorporated into the lattice of the reconstructed HAP at around $500^{\circ} \mathrm{C}$. The intensity of the $\mathrm{CO}_{3}^{2-}$ ion in FTIR decreased as the temperature increased and disappeared at around $900^{\circ} \mathrm{C}$. Above $1000^{\circ} \mathrm{C}$, reconstructed HAP lost $\mathrm{OH}$ ions and were transformed into oxyhydroapatite.

\section{Acknowledgements}

Authors are grateful to the National Sciences Council for their financial support to this research. The enthusiasm and knowledgeability of my colleagues and comrades-inarms inspired many improvements in this study. We would like to say thanks to those who greatly contributed to the project.

\section{References}

[1] M. Jarcho, Calcium phosphate ceramics as hard tissue prosthetics, Clin. Orthop. Relat. Res. 157 (1981) 259-278.

[2] H. Aoki, Medical Application of Hydroxyapatite, Ishiyaku Euro America Press, Tokyo, 1994, 1 p.

[3] K. de Groot, Bioceramics of Calcium Phosphate, CRC Press, Boca Raton, FL, 1983, 99 pp.

[4] K. de Groot, R. Geesink, C.P.A.T. Klein, P. Serekian, Plasma sprayed coating of hydroxyapatite, J. Biomed. Mater. Res. 21 (1990) 1375-1381.

[5] P. Ducheyne, S.R. Radin, M. Heughebaert, J.C. Heughebaert, Calcium phosphate ceramic coatings on porous titanium: effect of 
structure and composition on electrophoretic deposition, vacuum sintering and in vitro dissolution, Biomaterials 11 (1990) 224-254.

[6] B. Koch, J.G.C. Wolke, K. de Groot, X-ray diffraction studies on plasma-sprayed calcium phosphate-coated implants, J. Biomed. Mater. Res. 24 (1990) 665-667.

[7] J. Weng, X. Liu, X. Zhang, Z. Ma, X. Ji, Z. Zyman, Further studies on the plasma-sprayed amorphous phase in hydroxyapatite coatings and its demorphization, Biomaterials 14 (1993) 578-582.

[8] Z. Zyman, J. Weng, X. Liu, X. Li, X. Zhang, Phase and structural changes in hydroxyapatite coatings under heat treatment, Biomaterials 15 (1994) 151-155.

[9] K.A. Gross, C.C. Berndt, H. Herman, Amorphous formation in plasma-sprayed hydroxyapatite coatings, J. Biomed. Mater. Res. 39 (1998) 407-414.

[10] K.A. Gross, C.C. Berndt, Thermal processing of hydroxyapatite for coating production, Biomaterials 39 (1998) 580-587.

[11] S.R. Radin, P. Ducheyne, The effect of calcium phosphate ceramic composition and structure on in vitro behavior: I. Dissolution., J. Biomed. Mater. Res. 27 (1993) 25-34.

[12] J. Chen, W. Tong, C. Yang, J. Feng, X. Zhang, Effect of atmosphere on phase transformation in plasma-sprayed hydroxyapatite coatings during heat treatment, J. Biomed. Mater. Res. 34 (1997) 15-20.

[13] J. Chen, J.G.C. Wolke, K. de Groot, Microstructure and crystallinity in hydroxyapatite coatings, Biomaterials 15 (1994) 396-399.

[14] R. McPherson, N. Gane, T.J. Bastow, Structural characterization of plasma-sprayed hydroxylapatite coatings, J. Mater. Sci.: Mater. Med. 6 (1995) 327-334.

[15] B. Locardi, U.E. Pazzaglia, C. Gabbi, B. Profilo, Thermal behaviour of hydroxyapatite intended for medical applications, Biomaterials 14 (1993) 437-441.
[16] P.E. Wang, T.K. Chaki, Sintering behaviour and mechanical properties of hydroxyapatite and dicalcium phosphate, J. Mater. Sci.: Mater. Med. 4 (1993) 150-158.

[17] P.V. Ribound, Composition and stability of apatites in the system CaO- $\mathrm{P}_{2} \mathrm{O}_{5}$-iron oxide $-\mathrm{H}_{2} \mathrm{O}$ at high temperature, Ann. Chim. 8 (1973) 381-390.

[18] L.C. Chow, Development of self-setting calcium phosphate cements, J. Ceram. Soc. Jpn. 99 (1991) 954-964.

[19] G. Bonel, J. Heughebaert, M. Heughebaert, J.L. Lacout, A. Lebugle, Apatitic calcium orthophosphates and related compounds for biomaterials preparation, in: P. Ducheyne, J.E. Lemons (Eds.), Bioceramics: Material Characteristics versus in vivo Behavior, The New York Academy of Sciences, New York, 1988, pp. 115-129.

[20] R.M. Biltz, E.D. Pellegrino, The composition of recrystallized bone mineral, J. Dent. Res. 62 (1983) 1190-1195.

[21] E.G. Nordstrom, K.H. Karlsson, Carbonate-doped hydroxyapatite, J. Mater. Sci.: Mater. Med. 1 (1990) 182-184.

[22] L.G. Ellies, D.G. Nelson, J.D. Featherstone, Crystallographic structure and surface morphology of sintered carbonated apatites, J. Biomed. Mater. Res. 22 (1988) 541-553.

[23] L. Savarino, S. Stea, G. Ciapetti, D. Granchi, M.E. Donti, M. Cervellati, M. Visentin, A. Moroni, A. Pizzoferrato, The interface of bone microstructure and an innovative coating: an X-ray diffraction study, J. Biomed. Mater. Res. 40 (1998) 86-91.

[24] J. Weng, Q. Liu, J.G. Wolke, X. Zhang, K. de Groot, Formation and characteristics of the apatite layer on plasma-sprayed hydroxyapatite coatings in simulated body fluid, Biomaterials 18 (1997) 1027-1035.

[25] R.Z. LeGeros, M.S. Tung, Chemical stability of carbonate- and fluoride-containing apatites, Caries Res. 17 (1983) 419-429. 